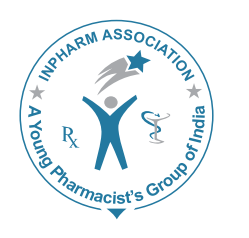

\title{
JVP
}

\section{Preparation and Evaluation of Silymarin $\beta$-cyclodextrin Molecular Inclusion Complexes}

\author{
Ghosh A, Biswas S, Ghosh T \\ Department of Pharmaceutics, Himalayan Pharmacy Institute, Majhitar, Rangpo, Sikkim, India \\ Address for correspondence: Dr.Amitava Ghosh; E-mail: amitoli@rediffmail.com
}

\begin{abstract}
Silymarin is a hepatoprotective agent, having poor water solubility and oral absorption of about $23-47 \%$, leading to low bioavailability of the drug. The aim of the present study is to improve the solubility and dissolution rate and in turn the hepatoprotective activity of the drug, by formulating its inclusion complex with beta ( $\beta$ )-cyclodextrin, using different methods. The phase solubility analysis indicates the formation of 1:1 molar inclusion complex of the drug with beta cyclodextrin. Apparent stability constant for Silymarin $\left(\mathrm{K}_{\mathrm{c}}\right)$ was $722 \mathrm{~K}^{-1}$ with $\beta$-cyclodextrin complex. The inclusion complexes were prepared by four different methods, namely, physical mixing, kneading, co-precipitation, and solvent evaporation. The prepared complexes were characterized using differential scanning colorimetry, scanning electron microscopy, and x-ray diffractometry. The inclusion complex prepared by the co-precipitation methods exhibits an overall best result, with respect to the formulation of sustained release formulations.
\end{abstract}

Key words: Bioavailability, inclusion complexes, silymarin, $\beta$-cyclodextrin

\section{INTRODUCTION}

Silymarin (482.43) is not a good water soluble hepatoprotective agent. The oral absorption of silymarin is only about $23-$ $47 \%$, leading to low bioavailability of the drug, which limits its use. It is a mixture of mainly three flavanolignans, namely, silybin, silydianin, and silicristine, with silybin being most active. silymarin has been used medicinally to treat liver disorders, including acute and chronic liver hepatitis, toxin-/drug-induced hepatitis and cirrhosis, and alcoholic

\begin{tabular}{|l|l|}
\hline \multicolumn{2}{|c|}{ Access this article online } \\
\hline Quick Response Code: & \\
\hline & Website: \\
\hline & www.jyoungpharm.in \\
& DOI: \\
\hline
\end{tabular}

Journal of Young Pharmacists Vol 3 / No 3 liver diseases. It is also reported to be effective in certain cancers. ${ }^{[1-5]}$ The poor aqueous solubility of the drug may lead to dissolution-related bioavailability problems. Many approaches such as solubilization with surfactant systems, formation of water soluble complexes, and use of pro-drugs and soluble salt formation have been reported for improving the solubility and dissolution, and in turn the bioavailability of the drug. ${ }^{[6-8]}$ Cyclodextrin and its derivatives play an important role in the formulation development due to their effect on solubility, dissolution rate, chemical stability, and absorption of a drug. ${ }^{[9]}$ Nagarsenkar et al. reported faster dissolution and better bioavailability of ketorolac solid dispersion with HP- $\beta-C D{ }^{[10]}$ Reddy et al. reported enhanced solubility and dissolution rate of Celecoxib by complexation with $\beta$-Cyclodextrin. ${ }^{[1]]}$ The objective of the present study is to investigate the possibility of improving the solubility and dissolution rate of silymarin by complexation with $\beta$-cyclodextrin and also to compare the different complexation methods with respect to their dissolution 
study. In addition, the physiochemical characteristics of solid inclusion complexes were also investigated.

\section{MATERIALS AND METHODS}

A gift sample of silymarin was obtained from AGAPE pharmaceuticals, Majhitar, East Sikkim; $\beta$-cyclodextrin was obtained from Zim Laboratories Ltd., Nagpur. HCl, methanol potassium dihydrogen phosphate, and sodium hydroxide were of analytical grade (Merck, Mumbai). All other chemicals and reagents used were of analytical grade.

Phase solubility analysis for silymarin

Phase solubility studies were performed to determine the stoichiometric proportions of silymarin with $\beta$-cyclodextrin. ${ }^{[12,13]}$ The data was used to determined the stability constant of the complexes. For this, the stock solution of $0.01 \mathrm{M} \beta$-cyclodextrin was prepared using distilled water. These stock solutions were diluted with distilled water to give molar solutions in the range of 0.002 to $0.01 \mathrm{M} \beta$-cyclodextrin. Five $\mathrm{ml}$ of each molar solution was filled in screw capped vials and the excess quantity of the drug was added to each vial separately. ${ }^{[7,14]}$ The vials were shaken at an ambient temperature, for 48 hours, using a laboratory shaker (Remi). The supernatant solutions were collected carefully and filtered using Whatman filter paper (No. 41). The concentration of the drug in filtered solutions was determined using a UV visible spectrophotometer. No changes in $\lambda$ max of the drug were found after complexation with cyclodextrin, hence absorbance of the resultant solutions were recorded at $286 \mathrm{~nm}$, which was $\lambda$ max of the drug. From the slope and intercept value $\left(\mathrm{S}_{0}\right)$ of the phase solubility curve, a stability constant $\left(\mathrm{K}_{c}\right)$ was determined.

$\mathrm{K}_{\mathrm{C}}=$ Slope $/\left[\mathrm{S}_{0}(1-\right.$ Slope $\left.)\right]$

Preparation of physical mixture and inclusion complexes

\section{Physical mixture method}

The required molar $(1: 1)$ quantities of the drug and cyclodextrin were weighted accurately and mixed together thoroughly in a mortar, with vigorous trituration, for about three hours. These mixtures were then passed through sieve No. 44, and finally stored in airtight containers till further use. ${ }^{[7,15,16]}$

\section{Kneading method}

The required quantities of the drug (Silymarin) and $\beta$-cyclodextrin were weighed accurately in a ratio of $1: 1$.
A homogenous paste of cyclodextrin was prepared in a mortar by adding water: Methanol mixture $(1: 1)$ in small quantities. Silymarin powder was then added to this paste in portions, with continuous kneading, for three hours. An appropriate quantity of water: Methanol mixture (1:1) was added further to maintain suitable consistency of the paste. This paste was dried in a hot air oven at $45^{\circ}-50^{\circ}$ for 24 hours. The dried complexes were then powdered and passed through sieve No. 44 and stored in airtight containers till further use. ${ }^{[15]}$

\section{Co-precipitation method}

Quantities of drug and cyclodextrin, in the required molar ratio $(1: 1)$, were dissolved in methanol : Water, respectively. The solution of the drug was added dropwise into cyclodextrin solution. The contents were continuously stirred for 6 hours and finally were dried at $45^{\circ}-50^{\circ}$ for 48 hours, collected, and stored in airtight containers till further use. ${ }^{[16]}$

\section{Solvent evaporation method}

In this technique, silymarin along with solubilizsing additives such as acetone were dissolved at $25^{\circ} \mathrm{C}$ temperature. Next, the required moles of $\beta$-cyclodextrin in hot distilled water were added dropwise into this solution, with continuous stirring, for one hour. The complexes formed were filtered and dried under a vacuum. Then the prepared solid mass was stored in a desiccator under vacuum to a constant weight. The dried products were removed, pulverized, and passed through sieve No. 100 and finally stored in a closed airtight container.

\section{Characterization of silymarin inclusion complexes}

\section{Drug content estimation}

The quantities of inclusion complex equivalent to $70 \mathrm{mg}$ of silymarin were dissolved in water: Methanol mixture (1:1). Appropriate dilutions were made and the drug content of each complex was calculated from UV absorbance recorded at $\lambda \max 286 \mathrm{~nm}$.

\section{Scanning electron microscopy}

The morphology of the inclusion complexes by physical mixture, kneading method, and co-precipitation method was studied using a scanning electron microscope (JSM5610 LV Jeol, Japan). The samples were coated with platinum to provide a conductive layer for observing images at $15 \mathrm{kV}$.

\section{IR spectrum analysis}

Infra red (IR) spectra of the drug and inclusion complexes were recorded using the $\mathrm{KBr}$ method using Fourier Transform Infrared Spectrophotometer (FT IR-8400 S). A baseline 
correction was made using dried potassium bromide, and then the spectra of the dried mixtures of drug and inclusion complexes with potassium bromide were recorded.

\section{Differential scanning calorimetric analysis}

This scanning was performed using DSC model (Perkin Elmer). The samples were placed in a closed platinum crucible and DSC thermograms were recorded at a heating rate of $10^{\circ}$ minute in the range of $20^{\circ}$ to $310^{\circ} \mathrm{C} \cdot{ }^{[16]}$

\section{X-ray diffraction study}

The X-ray diffraction pattern of the selected inclusion complex was compared with that of pure silymarin. This was performed by measuring $2 \theta$ in the range of $4^{\circ}$ to $50^{\circ}$ with reproducibility of $\pm 0^{\circ}-001^{\circ}$ on an $\mathrm{X}$-ray diffractometer (Phillips).

\section{Dissolution study of silymarin and its inclusion complexes}

Dissolution of inclusion complexes (equivalent to $70 \mathrm{mg}$ of silymarin) was studied using the USP XXII eight station dissolution apparatus (Electrolab TDT-08L). The dissolution was carried out in $900 \mathrm{ml}$ of Phosphate buffer, $\mathrm{pH}$ 6.8, at a speed of $75 \mathrm{rpm}$. Aliquots of $10 \mathrm{~mL}$ were withdrawn periodically and replaced with $10 \mathrm{~mL}$ of fresh dissolution medium. The concentrations of the drug in the samples were determined by measuring their absorbance at $286 \mathrm{~nm}$, using Shimadzu $1700 \mathrm{UV}$-visible spectrophotometer. Cumulative percent of the drug released was determined at every point of time. The pure drug was used as a control. The $\mathrm{T}_{90}$ (time required for $90 \%$ dissolution of drug) of various solid dispersions were

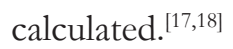

\section{RESULTS AND DISCUSSION}

\section{Phase solubility analysis of silymarin}

The phase solubility study was done to determine the stoichiometric proportion of silymarin with complexing agent $\beta$-cyclodextrin. The solubility analysis indicated the formation of a $1: 1$ molar inclusion complex of the drug with $\beta$-cyclodextrin. The apparent stability constant for silymarin $\left(\mathrm{K}_{c}\right)$ was $722 \mathrm{~K}^{-1}$ with the $\beta$-cyclodextrin complex.

\section{Characterization of silymarin inclusion complexes}

All the inclusion complexes prepared using different methods, such as, physical mixture, kneading method, coprecipitation, and solvent evaporation method were found to be slightly brown, free-flowing powders.

\section{Estimation of drug content}

Inclusion complexes prepared by co-precipitation showed nearly $100 \%$ drug content. The drug content of the inclusion complex prepared by kneading, physical mixture, and solvent evaporation shows slightly less drug content as compared to that prepared by using co-precipitation [Table 1].

\section{Scanning electron microscopy}

Scanning electron microscopy (SEM) of the physical mixture method, inclusion complex by kneading method, and coprecipitation method were studied. The representative photographs are shown in Figures 1-3. Pure drug particles in the physical mixture method were very small in size with reduced effective surface area, due to agglomeration. They remained dispersed and physically adsorbed on the surface of $\beta$-cyclodextrin. Figures 2 and 3, show drug particles distributed on the surface of $\beta$-cyclodextrin. Both kneaded and the co-precipitated systems show a homogeneity, signifying the inclusion complex formation. The kneaded system is of poor crystal structure, lacks distinct crystal faces, and has numerous cracks and fissures. This may also have contributed to faster dissolution compared to the co-precipitation system.

IR spectral analysis

Infra red spectra of the pure drug and inclusion of

Table 1: Comparison of drug content and $T_{90}$ value of silymarin inclusion complex with $\beta$-cyclodextrin

\begin{tabular}{lcc}
\hline Systems & \% Drug content & $\mathrm{T}_{90}(\mathrm{~min})$ \\
\hline Silymarin (alone) & - & $<120$ \\
Silymarin : $\beta$ cyclodextrin $(\mathrm{PM})$ & 97.140 & 62 \\
Silymarin : $\beta$ cyclodextrin $(\mathrm{KN})$ & 91.420 & 47 \\
Silymarin : $\beta$ cyclodextrin $(\mathrm{CP})$ & 99.995 & 94 \\
Silymarin $: \beta$ cyclodextrin $(\mathrm{SE})$ & 97.135 & 92 \\
\hline
\end{tabular}

PM: Physical mixture, KN: Kneading, CP: Co-precipitation, SE: Solvent evaporation

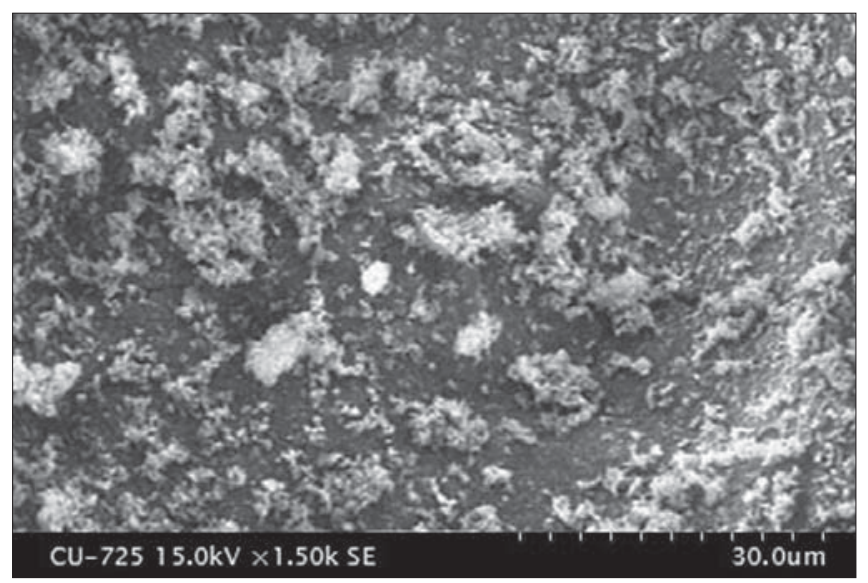

Figure 1: Silymarin with $\beta$-cyclodextrin (Physical mixture) 

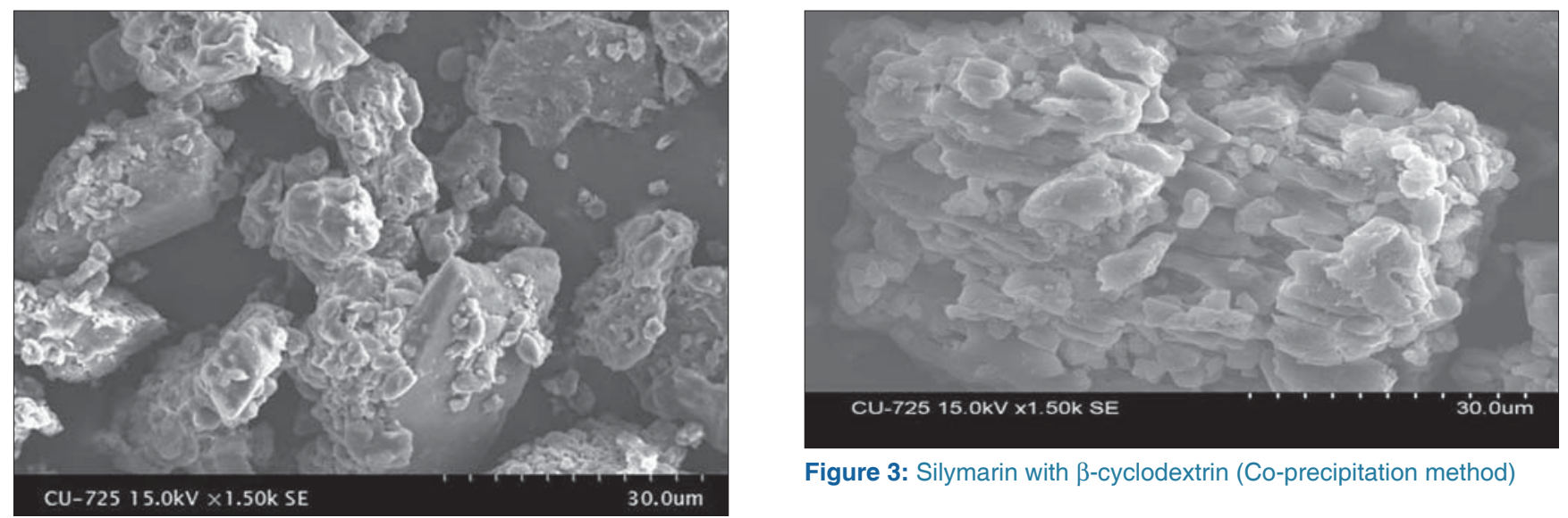

Figure 3: Silymarin with $\beta$-cyclodextrin (Co-precipitation method)

Figure 2: Silymarin with $\beta$-cyclodextrin (Kneading method)

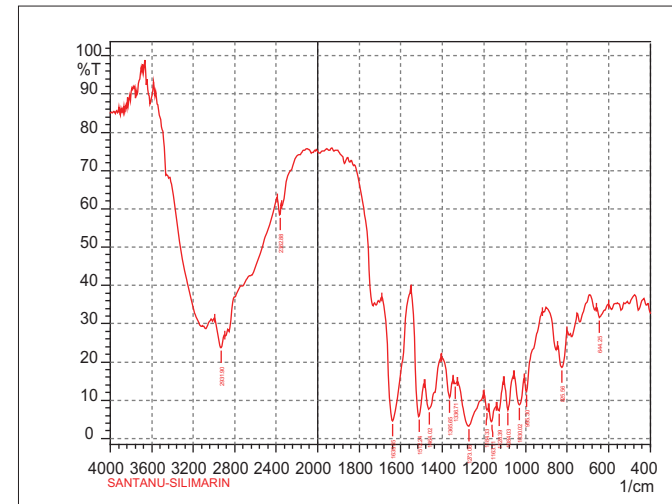

(a)

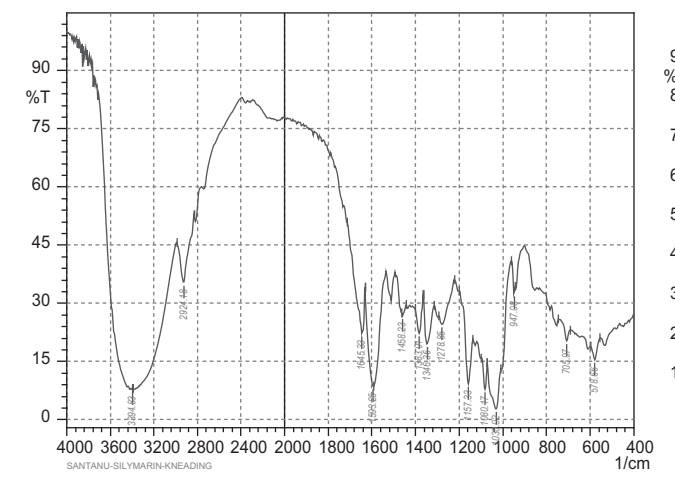

(c)

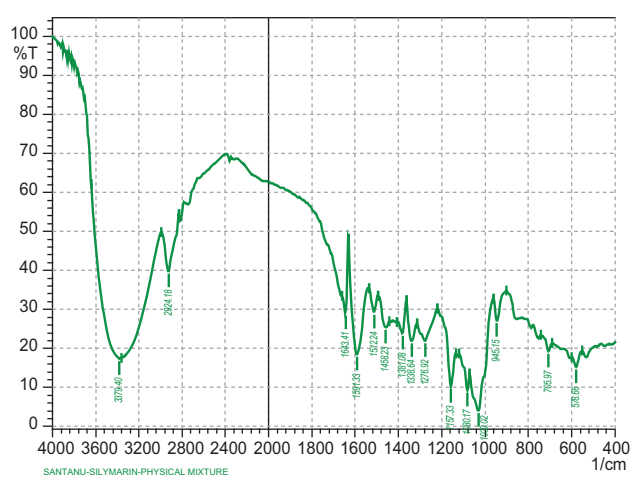

(b)

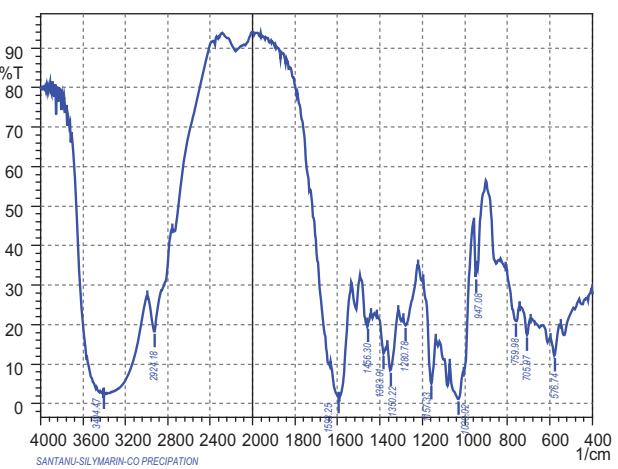

(d)

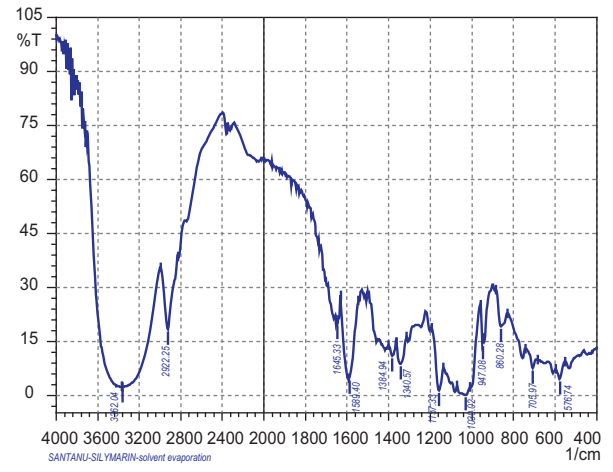

(e)

Figure 4: IR spectra of inclusion complexes of silymarin with $\beta$-cyclodextrin (a) FT IR study of silymarin (b) Physical mixture method (c) Kneading method (d) Co-precipitation method (e) Solvent evaporation 
silymarin with $\beta$-cyclodextrin, by different methods, are given in Figure $4(\mathrm{a}-\mathrm{e})$. The guest molecules within the cyclodextrin cavity show in their peaks or show peaks of less intensity. Basically peaks that lie in the fingerprint, and peaks due to $\mathrm{C}-\mathrm{O}$ or O-H stretching are affected (shifted or intensity is changed).

Differential scanning calorimetric analysis

Silymarin, $\beta$-cyclodextrin, and the complex prepared by the co-precipitation method were subjected to differential scanning calorimetric (DSC) analysis. The thermal curves are given in Figure 5. The DSC curve of silymarin shows one characteristic sharp endothermic peak at around $150^{\circ} \mathrm{C}$, indicating the melting point of the drug. The DSC curve shows that the sharp endothermic peak at around $150^{\circ} \mathrm{C}$, which is observed for silymarin, decreases in the inclusion complex (1:1). Furthermore, the wide peak at $90^{\circ} \mathrm{C}$, which is observed for $\beta$-cyclodextrin, shifts to $60^{\circ} \mathrm{C}$ in the inclusion complex, indicating that the inclusion complex does not contain much residue of silymarin or $\beta$-cyclodextrin, thus suggesting that the drug is well dispersed in the $\beta$-cyclodextrin cavity.

\section{X-ray diffraction study}

The inclusion complex of the drug prepared with $\beta$-cyclodextrin, using the co-precipitation method, which showed a good result overall, was characterized further by an XRD study The X-ray diffraction patterns of pure silymarin, as well as the silymarin- $\beta$-Cyclodextrin complex obtained by using the co-precipitation method are represented in Figure 6. The peak position (angle of diffraction) is an indication of the amorphous nature of the sample. The diffractogram of pure silymarin shows some intense peaks, which are indicative of crystallinity. However, in case of silymarin complexed with $\beta$-Cyclodextrin diffractogram, it attributes to a new solid phase with low

Table 2: Percentage cumulative release of inclusion complexes of silymarin and $\beta$-cyclodextrin prepared by different methods

\begin{tabular}{lccccc}
\hline Time & $\begin{array}{c}\text { \%CR } \\
\text { (Silymarin) }\end{array}$ & $\begin{array}{c}\text { \%CR } \\
(\mathbf{P M})\end{array}$ & $\begin{array}{c}\text { \%CR } \\
(\mathbf{K N})\end{array}$ & $\begin{array}{c}\text { \%CR } \\
(\mathbf{C P})\end{array}$ & $\begin{array}{c}\text { \%CR } \\
\text { (SE) }\end{array}$ \\
\hline 5 & 7.57 & 34.94 & 31.71 & 24.055 & 15.32 \\
15 & 14.20 & 49.56 & 53.52 & 27.481 & 39.25 \\
30 & 20.05 & 60.82 & 83.58 & 59.763 & 47.01 \\
45 & 23.45 & 80.61 & 99.08 & 66.686 & 77.05 \\
60 & 27.70 & 97.76 & - & 69.520 & 84.23 \\
75 & 32.79 & - & - & 87.200 & 86.41 \\
90 & 43.67 & - & - & 93.455 & 98.80 \\
105 & 46.34 & - & - & 95.320 & - \\
120 & 49.13 & - & - & - & - \\
\hline
\end{tabular}

PM: Physical mixture, KN: Kneading, CP: Co-precipitation, SE: Solvent evaporation crystallinity, indicating inclusion complex formation (more water soluble). A reduced number of signals, of markedly low intensity, are noticeable in the complex, indicating the greater amorphous nature of the inclusion complex compared to the free molecules.

Dissolution study of silymarin and its inclusion complexes

The inclusion complexes of silymarin with $\beta$-cyclodextrin produce pronounced enhancement in its dissolution as shown in Table 2 and Figure 7. From Table $1-\mathrm{T}_{90}$ value for kneading shows the quickest rate of dissolution as compared to the other inclusion complexes, prepared by

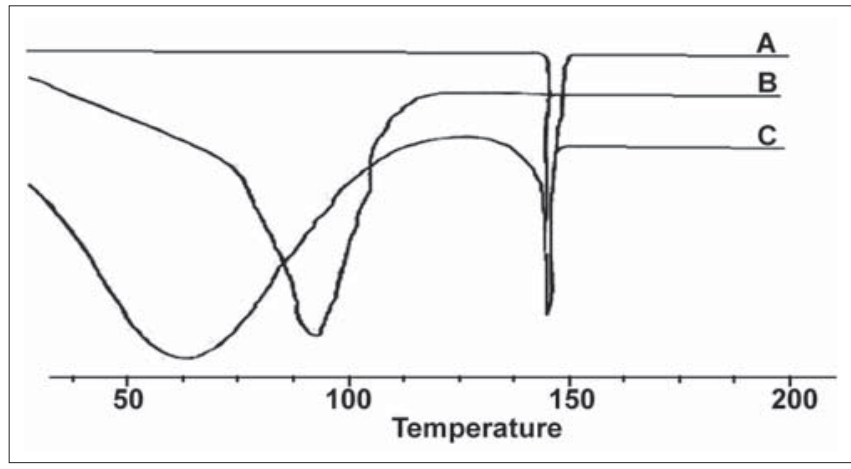

Figure 5: Differential scanning calorimetry study of silymarin, $\beta$-cyclodextrin and silymarin- $\beta$-cyclodextrin complex

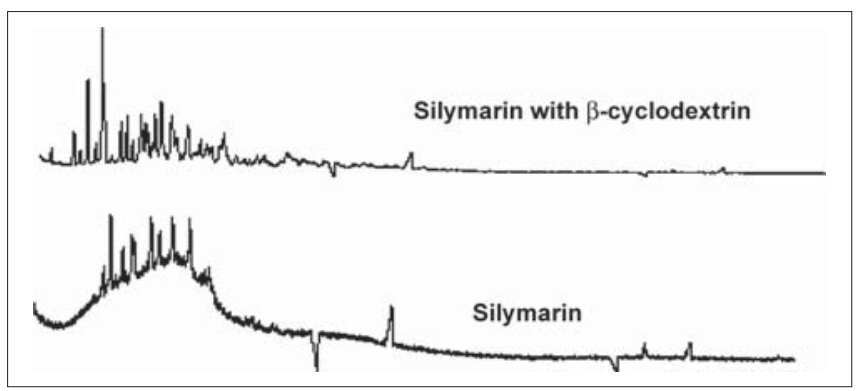

Figure 6: X-ray diffraction study on silymarin and silymarin complexed with $\beta$-cyclodextrin

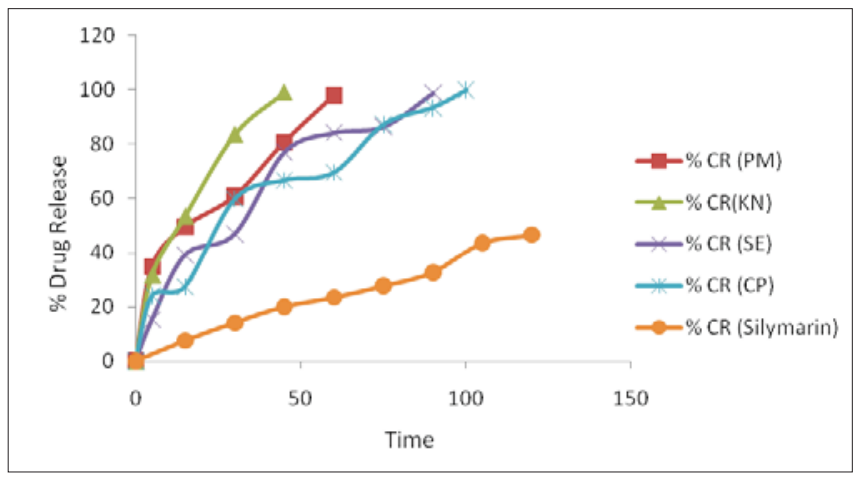

Figure 7: Dissolution profiles of inclusion complexes of silymarin and $\beta$-cyclodextrin prepared using different methods. $\mathrm{PM}=$ Physical mixture, $\mathrm{KN}=$ kneading, $\mathrm{CP}=$ co-precipitation, $\mathrm{SE}=$ solvent evaporation 
other inclusion methods. Inclusion complexes prepared by the co-precipitation methods show their $\mathrm{T}_{90}$ in about 94 minutes.

\section{CONCLUSION}

The phase solubility data suggest a $1: 1$ complex formation with $\beta$-cyclodextrin. All inclusion complexes show increase in dissolution than in the drug alone. The inclusion complex of the drug prepared by the co-precipitation method shows the best results overall, in terms of drug content and dissolution profile, for preparation of sustained release formulations. However, it should be noted that this is a result of a preliminary study of $\beta$-cyclodextrin inclusion complexation with silymarin.

\section{REFERENCES}

1. Luper SA. Review of plants used in the treatment of liver disease, Part 1. Altern Med Rev 1998;3:410-21.

2. Pradhan SC, Girish C. Hepatoprotective herbal drug, Silymarin from experimental pharmacology to clinical medicine. Indian J Med Res 2006;124:491-504.

3. Reynolds JE. Martindale the Extra Pharmacopoeia. London: Pharmaceutical Press; 2002.

4. Pepping J. Milk thistle: Silybum marianum. Am J Health Sys Pharma 1999;56:1195-7.

5. Saller R, Meier R, Brignoli R. The use of Silymarin in the treatment of liver diseases. Drugs 2001;61:2035-63.

6. Pinnamaneni S, Das N, Das SK. Formulation approaches for orally administered poorly soluble drugs. Pharmazie 2002;57:291-300.

7. Deshmukh SS, Potnis VV, Shelar DB, Mahaparale PR. Studies on inclusion complexes of ziprasone hydrochloride with $\beta$ cyclodextrin and hydroxypropyl $\beta$ cyclodextrin. Indian Drugs 2007;44:677-82.

8. Patil JS, Pandya NR, Marapur SC, Shiralashetti SS. Influence of method of preparation on physiochemical properties and in vitro drug release profile of nimodipine-cyclodextrin inclusion complexes: A comparative study. Int J Pharmacy Pharmaceutical Sci 2010;2:71-81.

9. Loftsson T, Brewster ME, Masson M. Role of cyclodextrins in improving oral drug delivery. Am J Drug Deliv 2004;2:1-15.

10. Nagarsenkar MS, Meshram R, Ramprakash G. Solid dispersion of hydroxypropyl a cyclodextrin and Ketorolac: Enhancement of in vitro dissolution rates, improvement in anti-inflammatory activity and reduction in ulcerogenecity in rats. J Pharm Pharmacol 2000;52:949-56.

11. Reddy MN, Chowdary KP, Diwan PV. $\beta$-Cyclodextrin complexes of celecoxib: Molecular modeling, characterization and dissolution studies. AAPS Pharm Sci 2004;6:E7.

12. Loftsson T, Brewster ME. Pharmaceutical application of cyclodextrin in drug solubilisation and stabilization. J Pharm Sci 1996;85:1017-25.

13. Kamal D, Ramana MD, Himaja M, Agarwal A, Garg V. Investigation of enhancement of solubility of norfloxacin beta cyclodextrin in presence of acidic solubilizing additives. Curr Drug Deliv 2007;4:21-5.

14. Attma AA, Ndibe ON, Nnamani PO. Studies on diclofenac- $\beta$-Cyclodextrin inclusion complexes. J Pharm Res 2004;3:47-9.

15. Soniwala MM, Patel PR, Ansuri MS, Parikh RK, Goel MC. Various approaches in dissolution enhancement of Rofecoxib. Indian J Pharm Sci 2005;67:61-3.

16. Aries MJ, Moyano JR, Munoz P, Justo A. Study of Omeprazole-gcyclodextrin complexation in the solid state. Drug Dev Ind Pharm 2000;26:253-9.

17. Becket G, Schep LJ, Tan MY. Improvement of the in vitro dissolution of praziquantel by complexation with $\alpha$-, $\beta$-, and $\gamma$-cyclodextrin. Int J Pharm 1999;179:65-71.

18. Bekers O, Uijtendaal EV, Beijnen JH, Bult A, Underberg WJ. Cyclodextrins in the pharmaceutical field. Drug Dev Ind Pharm 1991;17:1503-49.

How to cite this article: Ghosh A, Biswas S, Ghosh T. Preparation and evaluation of silymarin $\beta$-cyclodextrin molecular inclusion complexes. J Young Pharmacists 2011;3:205-10.

Source of Support: Nil, Conflict of Interest: None declared.

\section{Author Help: Online submission of the manuscripts}

Articles can be submitted online from http://www.journalonweb.com. For online submission, the articles should be prepared in two files (first page file and article file). Images should be submitted separately.

1) First Page File:

Prepare the title page, covering letter, acknowledgement etc. using a word processor program. All information related to your identity should be included here. Use text/rtt/doc/pdf files. Do not zip the files.

2) Article File:

The main text of the article, beginning with the Abstract to References (including tables) should be in this file. Do not include any information (such as acknowledgement, your names in page headers etc.) in this file. Use text/rtf/doc/pdf files. Do not zip the files. Limit the file size to $1024 \mathrm{~kb}$. Do not incorporate images in the file. If file size is large, graphs can be submitted separately as images, without their being incorporated in the article file. This will reduce the size of the file.

3) Images:

Submit good quality color images. Each image should be less than $\mathbf{4 0 9 6} \mathbf{~ k b ~ ( 4 ~ M B ) ~ i n ~ s i z e . ~ T h e ~ s i z e ~ o f ~ t h e ~ i m a g e ~ c a n ~ b e ~ r e d u c e d ~ b y ~ d e c r e a s - ~}$ ing the actual height and width of the images (keep up to about 6 inches and up to about $1800 \times 1200$ pixels). JPEG is the most suitable file format. The image quality should be good enough to judge the scientific value of the image. For the purpose of printing, always retain a good quality, high resolution image. This high resolution image should be sent to the editorial office at the time of sending a revised article.

4) Legends: Legends for the figures/images should be included at the end of the article file. 